\title{
La Última Comunión de San Fernando de Castilla (1683): continuando el catálogo del pintor sevillano Antonio Hidalgo
}

The last Communion of Saint Ferdinand of Castile (1683): continuing the catalog of the Sevillian painter Antonio Hidalgo

\author{
Jesús Porres Benavides ${ }^{1}$ \\ Universidad Rey Juan Carlos (Madrid) \\ Antonio Romero Dorado ${ }^{2}$ \\ Universidad de Sevilla
}

Resumen: Este trabajo presenta una obra firmada por Antonio Hidalgo, pintor de escuela sevillana activo entre 1664 y 1689. Se trata de la Última Comunión de San Fernando, una pintura realizada en 1683 y que se conserva en la Catedral Vieja de Cádiz.

Palabras clave: Antonio Hidalgo; Escuela sevillana de pintura; Última Comunión de San Fernando; Catedral Vieja de Cádiz.

\begin{abstract}
This paper discloses a painting signed by Antonio Hidalgo, an artist from the Seville School who was active between 1664 and 1689. It is a depiction of The Last Communion of Saint Ferdinand of Castile, a painting made in 1683 and preserved at the Old Cathedral of Cadiz.
\end{abstract}

Key words: Antonio Hidalgo; Seville School of painting; Last Communion of Saint Ferdinand of Castile; Old Cathedral of Cadiz.

\footnotetext{
${ }^{1}$ http://orcid.org/0000-0002-4042-7426

2 http://orcid.org/0000-0002-4979-0491

(C) 2018 Philostrato. Revista de Historia y Arte
} 


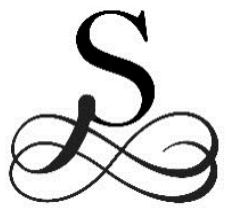

egún los documentos conocidos hasta la fecha, el pintor sevillano Antonio Hidalgo estuvo profesionalmente activo entre 1664 y 1689 . Sin embargo, por el momento solo se ha publicado una de sus obras. Nos referimos al lienzo de las Ánimas del Purgatorio que se conserva en la iglesia parroquial de Santa Catalina, en Conil de la Frontera (fig.1) ${ }^{3}$. Por ello, con el presente trabajo venimos a ampliar el catálogo del artista dando a conocer una nueva obra firmada por él. Se trata de la Última Comunión de San Fernando, una pintura que se conserva en la Catedral Vieja de Cádiz y que actualmente es la Parroquial de Santa Cruz (fig. 2).

El registro textual más antiguo que conocemos sobre la existencia de la pintura es de 1690, cuando Fray Jerónimo de la Concepción publicó su Emporio del Orbe: Cádiz Ilustrada. El carmelita descalzo nos informa de que entonces el lienzo ya estaba en la Catedral de Cádiz, en concreto al lado del altar de la Cofradía de las Ánimas, que se levantaba sobre el muro de los pies del templo, junto a la puerta de la iglesia, en el lado de la Epístola ${ }^{4}$. Además, Fray Jerónimo de la Concepción nos describe la pintura como "un hermoso y majestuoso cuadro del tránsito del Santo Rey Don Fernando", informándonos de que allí lo puso el Arcediano de Medina Sidonia, D. José Rabaschiero y Fiesco. En efecto, la iniciativa y parte del dinero necesario debieron de ser del arcediano, pero sabemos por documento que la pintura fue costeada con las limosnas de varios particulares y que el cuadro fue colocado en su lugar el 3 de septiembre de 1683 , el mismo año en que suponemos fue pintado ${ }^{5}$. Posteriormente, la pintura fue trasladada a la capilla del Sagrario, puede que en 1770 , con motivo de su inauguración, porque en 1806 ya figura en los inventarios como colgada en sus muros ${ }^{6}$. Como es natural, debemos identificar esta obra con la pintura de la Última Comunión de San Fernando, que actualmente se encuentra en la Capilla de los Guipuzcoanos y Vizcaínos, situada en el brazo del crucero del lado de la Epístola.

Se trata de una pintura realizada al óleo sobre lienzo, de $240 \times 160 \mathrm{~cm}$. En el centro de la composición se representa al rey Fernando III de Castilla recibiendo la que sería su última comunión antes de morir, en sus aposentos del Real Alcázar de Sevilla. El monarca, que aparece arrodillado junto a su lecho, está ricamente vestido con capa roja forrada de armiño y se dispone a recibir la sagrada forma con un paño en las manos. Ante el rey se yergue la figura de su confesor, Don Remondo, vestido con lujosa capa pluvial y respaldado por una cruz patriarcal o arzobispal. ${ }^{7}$ El eclesiástico porta un cáliz

\footnotetext{
3 Antonio Romero Dorado, "Iniciando el catálogo del pintor Antonio Hidalgo: las Ánimas del Purgatorio (1688)", Philostrato, no 2, (2017), pp. 65-69.

${ }^{4}$ Fray Jerónimo de la Concepción, Emporio del Orbe: Cádiz Ilustrada (Ámsterdam, 1690), pp. 572-573.

${ }^{5}$ Fernando Quiles García y Lorenzo Alonso de la Sierra Fernández, "Nuevas obras de Cornelio Schut el Joven", Norba: Revista de Arte, no 18-19, (1998-1999), pp. 83-104, aquí p. 92; Información procedente del Archivo Catedralicio de Cádiz (en adelante A.C.C.), libro XIII, fol. 25 vo.

${ }^{6}$ Ibídem. Información procedente del A.C.C., Sección 3, libro 4, Inventario de 1806, fol. 54 vo.

7 Sabemos que Don Remondo, también conocido como Raimundo de Losana, obispo de Segovia desde 1249 , notario y confesor del rey Fernando III, fue quien dio al monarca su última comunión. Aunque en la pintura de Hidalgo Don Remondo aparece representado como arzobispo, lo cierto es que se trata de
} 
dorado y le ofrece la ostia al rey, que la mira con ojos piadosos. A espaldas de Don Remondo, se dispone una mesa de altar que sostiene un blandón y que está respaldada por un dosel rojo cuya parte superior muestra el escudo de la corona castellano-leonesa. En el primer plano, sobre un enlosado blanco y negro, representado en perspectiva, aparece un almohadón de terciopelo rojo, con cenefa y borlas doradas, sobre el que reposan las insignias reales (corona y cetro), así como una espada, atributo del monarca como conquis-

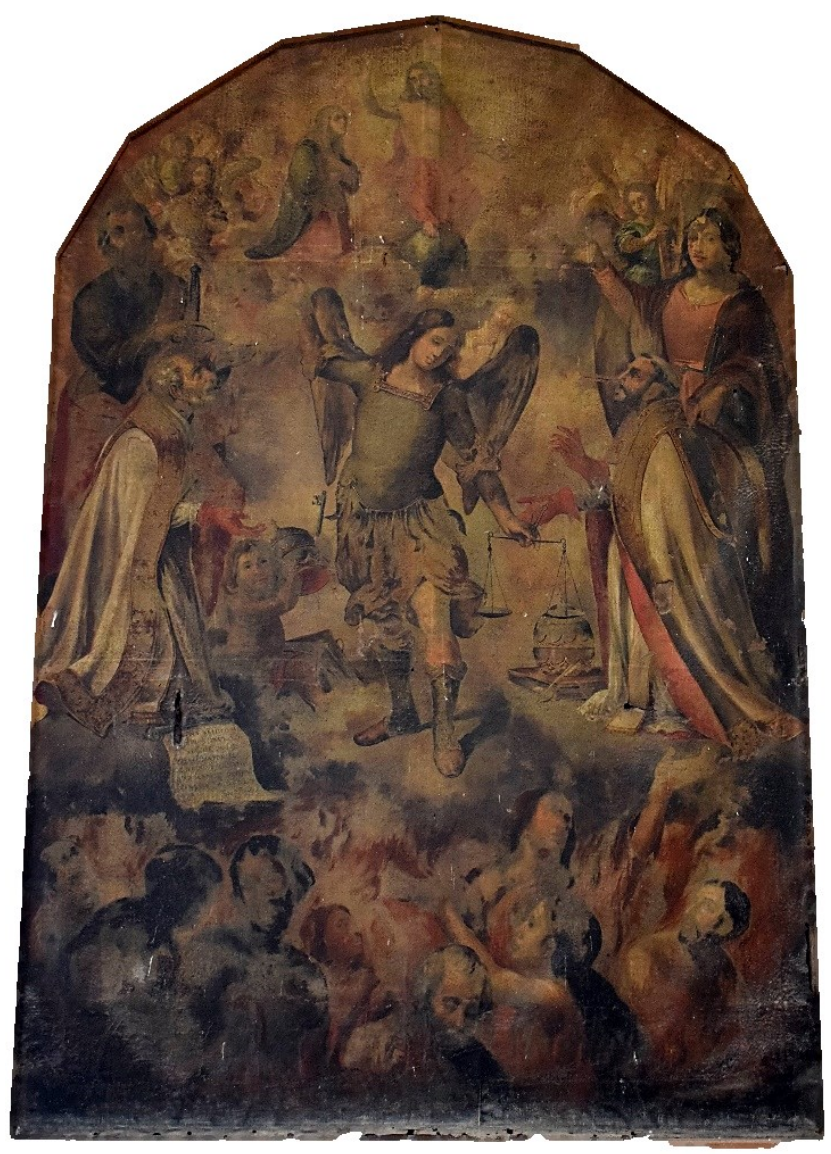

Fig. 1. Antonio Hidalgo, Las Ánimas del Purgatorio (1688), iglesia de Santa Catalina, Conil de la Frontera (Cádiz) [Fotografía autorC]

tador. A la derecha, un niño ministril sostiene en sus manos el lavabo y sobre un hombro el manutergio, para la ablución litúrgica, mientras que a la izquierda se observan dos miembros de la corte debidamente arrodillados. Sobre el Rey y Don Remondo hay un rompimiento de gloria en el que se

una imagen anacrónica o extemporánea, porque no alcanzó la dignidad arzobispal hasta 1258, varios años después de la muerte de San Fernando, acontecida en 1252. Por entonces, el verdadero arzobispo de Sevilla era el infante Don Felipe de Castilla, hijo del rey. Sin embargo, se considera que Don Felipe, aunque nombrado, nunca llegó a ejercer verdaderamente el cargo de arzobispo, siendo Don Remondo el encargado de organizar la recién conquistada archidiócesis. De hecho, años después, en 1258, cuando el Infante Felipe casó con la Princesa Cristina de Noruega, renunciando por ello a la mitra hispalense, Don Remondo fue nombrado arzobispo de Sevilla, cargo que ejerció hasta 1286, pasando a la historia como el verdadero restaurador de la Iglesia de Sevilla.; AA.VV., Historia de la Iglesia de Sevilla, (Sevilla-Barcelona, 1992), pp. $108,119,829$. 
sitúan varios ángeles volanderos, que portan palmas, coronas y ramilletes de flores.

Respaldando las figuras principales se dispone una multitud de caballeros cortesanos, sobriamente vestidos, que son testigos de la escena mostrando diferentes actitudes, entre los que destaca el personaje que enjuga sus lágrimas con un pañuelo. Esta multitud de personajes, pertenecientes a la cámara del rey, van perdiéndose por el lado izquierdo de la pintura a través de un espacio arquitectónico indefinido que se abre a un paisaje. Este acertado recurso dota al cuadro de mayor profundidad, lo que contrasta con la perspectiva del dosel de la cama, que resulta forzada. El lecho está respaldado por un elaborado cabecero dorado, mientras que el dosel que lo cubre, realizado en seda brocada con motivos florales, está orlado por cenefas de hilo de oro. Paradójicamente, el uso de hojas de pan de oro en las cenefas del dosel, enfatiza visualmente la falta de pericia en el dibujo de este elemento, si bien hay que admitir que se trata de un aspecto técnico bastante original dentro de su contexto geográfico y cronológico. Asimismo, resulta especialmente interesante la figura del niño que lleva en sus manos el lavabo litúrgico, que parece casi directamente tomada de la Circuncisión de Zurbarán, en el Museo de Grenoble (1639), procedente de la Cartuja de Jerez de la Frontera ${ }^{8}$. El carácter claramente admonitorio de la figura de Zurbarán, que mira directamente al espectador, está ligeramente atenuado en el caso del paje de Hidalgo, cuya mirada parece algo más esquiva.

En cuanto al estado de conservación de la pintura, evidencia claras deficiencias. La obra tiene una indudable capa de suciedad y barnices antiguos que distorsionan en gran medida la imagen que presenta. Pero el principal problema es que la tela parece haber sufrido los daños de una antigua forración, que le ha provocado considerables deformaciones. Sin embargo, podemos decir que la capa pictórica original se conserva bastante bien, sin apenas lagunas ni repintes.

Hasta el momento, los autores han atribuido esta pintura tanto a Juan de Valdés Leal ${ }^{9}$ como a Juan Gómez Couto ${ }^{10}$, pero el estilo de estos artistas no encaja con lo que vemos en la Última Comunión de San Fernando. Es cierto que existen numerosos puntos de contacto con Valdés Leal, en los tipos humanos usados, así como en la teatralidad de la composición, el abigarramiento de personajes y en cierto tenebrismo. Por ello, esta obra ha llegado a compararse con la "Apoteosis de San Fernando" de la catedral de Jaén, encargada por su cabildo y realizada por Valdés Leal entre 1673 y 1674 ,

\footnotetext{
${ }^{8}$ Debemos y agradecemos a D. José Manuel Moreno Arana esta acertada observación. En el caso del paje de la pintura de Zurbarán, se ha hablado de que la fuente grabada podría haber sido la estampa de correspondiente a la Circuncisión, de las Imágenes de la Historia Evangélica, del Padre Nadal, aunque debemos decir que la inspiración nos parece algo vaga. E R. Cunnar, "Jerome Nadal and Francisco Pacheco: A print and a verbal source for Zurbarán's Circuncision", Boletín del Museo e Instituto Camón Aznar, 33, (1988), pp. 105-112.

9 Juan Antonio Fierro Cubiella, "Un cuadro de Santa Cruz ¿obra de Valdés Leal?", Diario de Cádiz, (7 de marzo de 2000), p. 34.; Pablo Antón Solé, Las catedrales de Cádiz y su museo, (Barcelona, 2001), p. 20. ${ }^{10}$ Lorenzo Alonso de la Sierra Fernández y Juan Alonso de la Sierra Fernández, Guía artística de Cádiz y su provincia, (Sevilla, 2005), tomo 1, p. 30.
} 
tras la canonización del santo en $1671^{11}$. Sin embargo, el parangón con Valdés Leal parece fuera de lugar, y debemos afirmar que la mayoría de los elementos comunes entre ambas pinturas son consustanciales a los modos propios de la escuela sevillana del Barroco. La cuestión de la autoría se resolvió finalmente en 2007, pues en la obra apareció la firma de Antonio Hidalgo. El hallazgo se produjo durante una operación de limpieza superficial, que se hizo para la exposición que se celebraría en la iglesia de Santa Cruz, enmarcada en el proyecto Andalucía Barroca ${ }^{12}$. Dentro de los preparativos de la muestra, se realizó una limpieza superficial del mismo ${ }^{13}$, en la cual se encontró en la parte inferior derecha del lienzo una firma que dice: $D$. Antonio Hidalgo faciebat (fig. 3), que coincide en lo fundamental con la grafía de la rúbrica hallada en Conil (fig. 4).

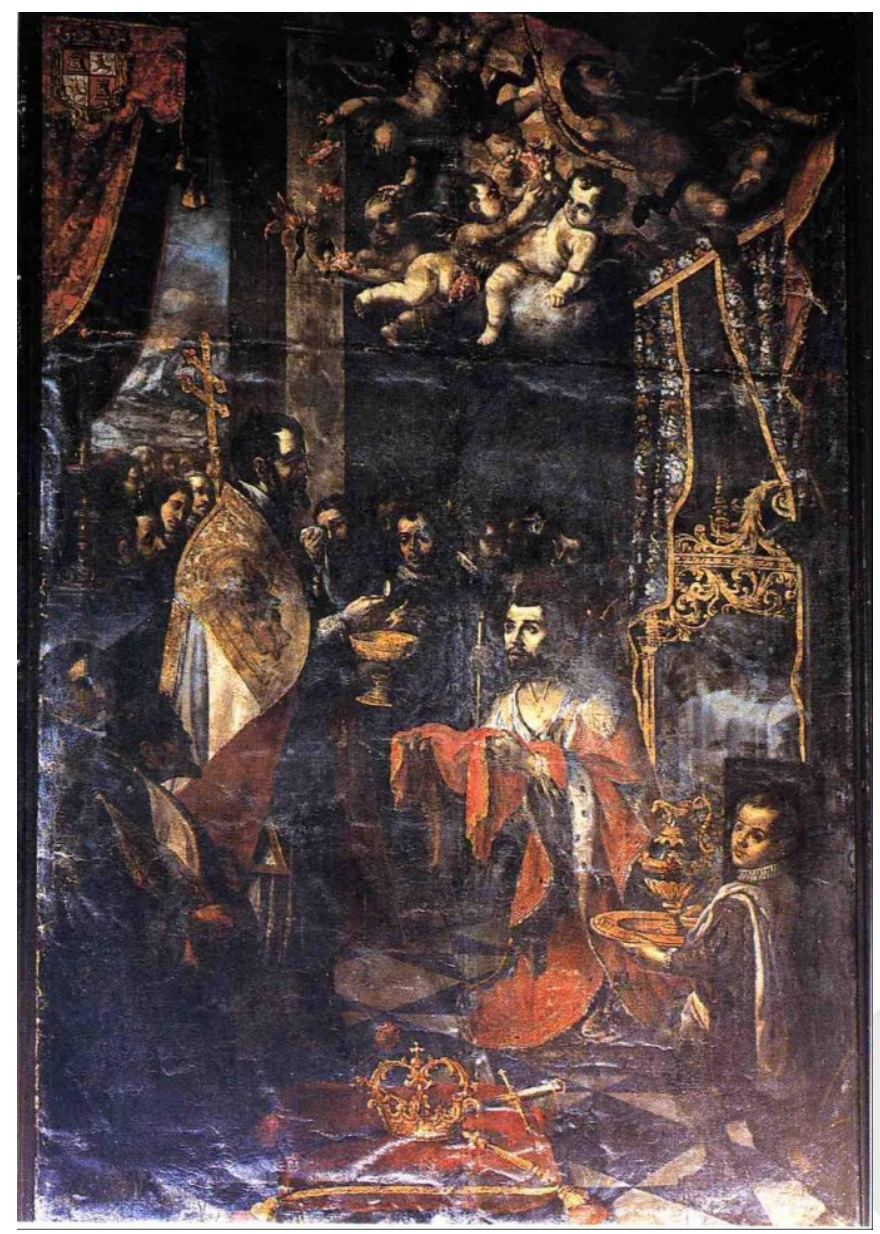

Fig. 2. Antonio Hidalgo, La Última Comunión de San Fernando (1683), Catedral Vieja de Cádiz [Fotografía autores $\subset$ ]

\footnotetext{
${ }^{11}$ Sobre esta obra véase: Enrique Valdivieso, Pintura barroca Sevillana (Sevilla, 2003), p. 469.

12 AA.VV. La Imagen Reflejada. Andalucía, Espejo de Europa. (Iglesia de Santa Cruz de Cádiz. 12 de noviembre de 2007-30 de enero 2008), (ed. Sevilla, 2007).

13 Por Fabián Pérez y Jesús Porres.
} 
Gracias a ello, en 2009, cuando la Catedral Vieja de Cádiz se inscribió como Bien de Interés Cultural, en el inventario de sus bienes muebles se consignó que el autor de nuestra pintura era Antonio Hidalgo y se dató la obra hacia 1670-169914. Sin embargo, el dato no tuvo mayor trascendencia ni desarrollo historiográfico, de manera que años después, en 2014, se interpretaba que la firma debía de pertenecer a Nicolás Antonio José Hidalgo González (17161789), un pintor nacido en Villanueva de la Serena ${ }^{15}$. Comoquiera que este artista extremeño había vivido en el siglo XVIII, mientras que el registro más antiguo que tenemos de la pintura es de 1683, se interpretó que Hidalgo González debió de estampar su firma sobre la obra tras haberla "restaurado" 16. Con esta errónea interpretación, se volvía de forma atávica a la antigua atribución a Valdés Leal, regresando al punto de partida y dejando de nuevo a la obra huérfana de padre. Este error debemos achacarlo al generalizado desconocimiento del pintor sevillano Antonio Hidalgo, activo entre 1664 y 1689 , pues debemos recordar que este artista no solo ha sido confundido con el extremeño Nicolás Antonio José Hidalgo González (1716-1789), sino también con el valenciano José García Hidalgo (1645-1717); en el caso de este último, a propósito de una Inmaculada Concepción del Museo del Prado firmada "HIDALGO" 17.

Con respecto al sevillano Antonio Hidalgo, autor de la Última Comunión de San Fernando (1683) y de las Ánimas del Purgatorio (1688), aunque por el momento desconocemos su lugar de nacimiento, debemos presuponerlo hispalense, en sentido amplio, en tanto que pudo nacer en la ciudad de Sevilla o en alguno de los municipios de su reino $y$, en cualquier caso, porque su obra pertenece a la escuela sevillana de pintura. En cuanto a las circunstancias de su formación artística, el conde de la Viñaza creyó que era discípulo de Pedro de Camprobín ${ }^{18}$. Lo cierto es que la noticia documental más antigua que tenemos de nuestro autor es de 1664, cuando compareció en Sevilla como testigo en la redacción del testamento del pintor Bernabé de Ayala. Ambos artistas fueron miembros de la Academia del Arte de la Pintura, fundada en la ciudad por Murillo y Herrera el Mozo. Entre 1668 y 1674, constan varios pagos que Hidalgo realizó en dicha institución, destacando la contribución de 8 reales que hizo en 1671 para el funeral del $1^{\circ}$ conde de los Arenales, D. Juan Fernández de Henestrosa, protector de la Academia, de la que Hidalgo figura como escribano público en $1674^{19}$. Ese mismo año entró en su taller como aprendiz Diego Lucas de Mesa, en su casa de la collación de San Salvador, mientras que al año siguiente lo hizo Diego Sáenz Cabezón, en la de San Andrés, por un periodo de cinco y cuatro años, respectivamente 20 . No obstante, al poco tiempo, quizá concluida la formación

\footnotetext{
${ }^{14}$ Boletín Oficial de la Junta de Andalucía (BOJA), Boletín número 113 de 15/06/2009, p. 56.

${ }^{15}$ Ferro Cubiella, Diario de Cádiz, 2 de mayo de 2014.

${ }^{16}$ Ibidem

17 Número de inventario: P03207. Óleo sobre lienzo, $205 \times 155 \mathrm{~cm}$.

${ }^{18}$ Conde de la Viñaza, Adiciones al diccionario histórico de Ceán Bermúdez. Vol. II, (Madrid, 1889), p. 283.

${ }^{19}$ Duncan T. Kinkead, Pintores y doradores en Sevilla: 1650-1699. Documentos. $2^{a}$ ed. rev., (Bloomington, 2009), pp. 245-246; Ramón Corzo Sánchez, La Academia del Arte de la Pintura de Sevilla, 1660-1674, (Sevilla, 2009), p. 77.

${ }^{20}$ Kinkead, Pintores y doradores, p. 246.
} 
de sus aprendices, se instaló en Cádiz, donde ya figura el 27 de marzo de 1680 , demandando junto a otros diecinueve pintores de la ciudad que las pinturas fueran exoneradas de impuestos municipales. En Cádiz, debió recibir numerosos encargos de instituciones religiosas de su diócesis y particulares, entre los que por ahora conocemos la Última Comunión de San Fernando, pintada en 1683 para la Catedral y las Ánimas del Purgatorio, realizada en 1688 para la hermandad de dicho nombre de Conil. La última noticia que tenemos de Hidalgo es de 1689, figurando como albacea, junto a Bernabé de Ayala, en el testamento del pintor Miguel Legot, hijo de Pablo ${ }^{21}$. Finalmente, es probable que Hidalgo, como otros pintores de formación sevillana trasladados a Cádiz, falleciera en esta última ciudad.

La imagen que hasta el momento teníamos de Hidalgo estaba fuertemente condicionada por lo que nos había trasmitido el conde de la Viñaza, que lo consideró discípulo de Camprobín. Solo se tenía noticia de dos obras suyas no localizadas: dos floreros que habían formado parte de la colección de Saturnino Dominé, en Sevilla22. Por ello, la historiografía lo veía como un simple pintor de flores, especializado en bodegones. En palabras de Viñaza, las flores de esos cuadros "son delgadas y tienen un colorido muy brillante, gran fuerza de empastado y tocadas con espíritu y valentía". A falta de flore-

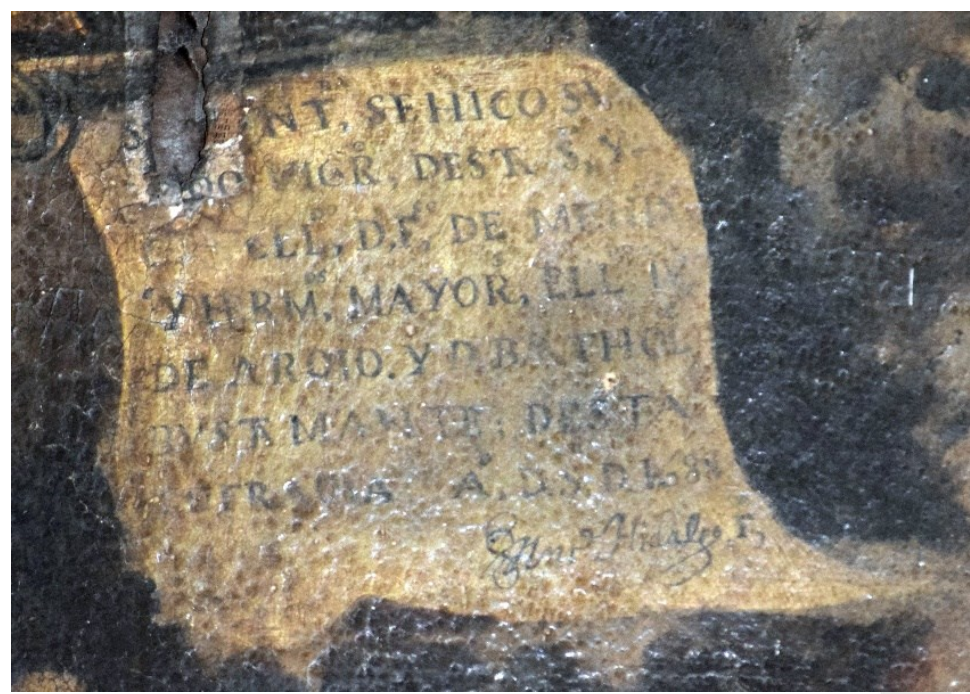

Fig. 3. Antonio Hidalgo, Detalle de la firma del pintor en las Ánimas del Purgatorio, Conil de la Frontera (Cádiz) (Fotografia autor $($ )

ros conservados de mano de Hidalgo, podemos observar esta capacidad suya para la representación vegetal, en el rompimiento de gloria de la última Comunión de San Fernando, donde se observa la soltura con que trata las flores que sostienen el grupo de ángeles volanderos. Ahora, con la publicación

\footnotetext{
${ }^{21}$ Eduardo Lamas-Delgado, "Le peintre Bernabé de Ayala et autres petits maîtres entre Séville et Cadix", Annales d'Histoire de l'art et d'archéologie, no 36, (2014), pp. 71-94; Eduardo Lamas-Delgado, "El pintor Miguel Legot (Sevilla, c. 1627-Cádiz, 1695)", El Rincón malillo, no 5, (2015), pp. 47-52.

22 Andrés Sánchez López, La pintura de bodegones y floreros en España en el siglo XVIII. (Tesis doctoral: Madrid, Universidad Complutense, 2006), p. 69.
} 
de dos de sus composiciones de gran formato y de numerosas figuras, debemos revisar la imagen que teníamos de él, sin menoscabo de seguir considerando su capacidad como pintor de floreros, pero insertándolo con decisión, como una interesante figura, dentro de la problemática general de los pintores sevillanos establecidos en Cádiz en la segunda mitad del siglo XVII 23 .

Para finalizar, las obras de Hidalgo conocidas, tan solo dos y mal conservadas, nos impiden abordar el tema de su posible influencia en otros artistas. Con todo, podemos suponer que el arte de Diego Lucas de Mesa y Diego Sáenz Calderón, los dos discípulos de Hidalgo documentados, derivara directamente de la obra de su maestro, no obstante, nada conocemos del catálogo de estos dos pintores. Del mismo modo, a pesar de que los documentos prueban la relación de Hidalgo con otros pintores del ámbito hispalense-gaditano de la segunda mitad del siglo XVII, caso de Bernabé de Ayala y Miguel Legot, no podemos aventurarnos a establecer relaciones estilísticas entre ellos, toda vez que la pintura de Legot hijo nos es totalmente desconocida y que la obra conocida de Ayala está totalmente imbuida dentro de lo zurbaranesco, estética totalmente ajena a lo que hasta ahora conocemos de Hidalgo, que parece bascular entre la pintura de Valdés Leal y lo murillesco, cuyo conocimiento, no obstante, se ha ampliado notablemente con la exposición "Murillo y su estela en Sevilla", recientemente clausurada.

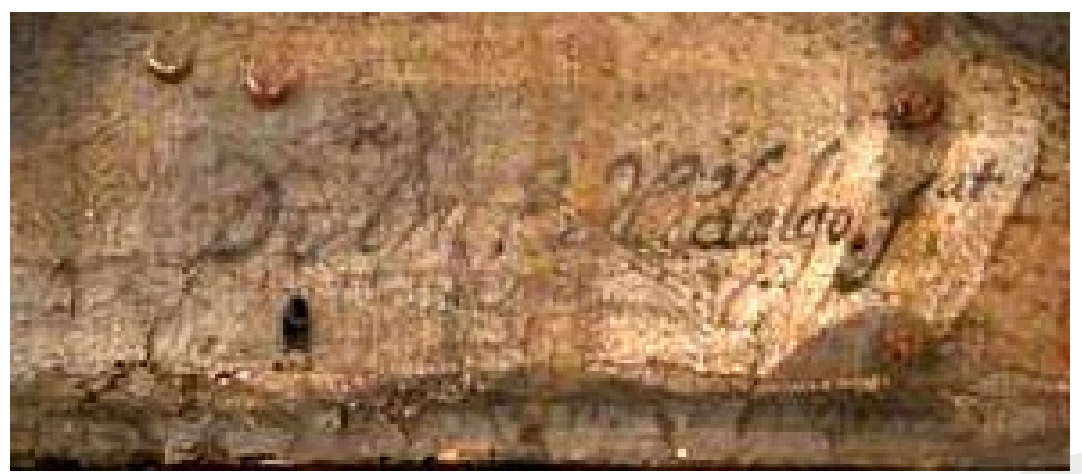

Fig. 4. Antonio Hidalgo, Detalle de la firma de la Última Comunión de San Fernando, Cádiz (Fotografía autor (C)

${ }^{23}$ Lamas-Delgado, Peintre Bernabé de Ayala. 
Bibliografía:

Alonso de la Sierra Fernández 2005: Lorenzo Alonso de la Sierra Fernández y Juan Alonso de la Sierra Fernández, Guía artística de Cádiz y su provincia, (Sevilla: Fundación José Manuel Lara, 2005), tomo 1.

Antón Solé 2001: Pablo Antón Solé, Las catedrales de Cádiz y su museo, (Barcelona: Escudo de Oro, 2001).

Autores varios 1992: Autores varios, Historia de la Iglesia de Sevilla, (SevillaBarcelona: Editorial Castillejo, 1992.).

Cádiz 2007: La Imagen Reflejada. Andalucía, Espejo de Europa. Iglesia de Santa Cruz de Cádiz, exposición celebrada del 12 de noviembre de 2007 al 30 de enero 2008, (ed. Sevilla: Junta de Andalucía, 2007).

Corzo Sánchez 2009: Ramón Corzo Sánchez, La Academia del Arte de la Pintura de Sevilla, 1660-1674, (Sevilla: Instituto de Academias de Andalucía, 2009).

Cunnar 1988: Eugene R. Cunnar, "Jerome Nadal and Francisco Pacheco: A print and a verbal source for Zurbarán's Circuncision", Boletín del Museo e Instituto Camón Aznar, 33, 1988, p. 105-112.

Fierro Cubiella 2000: Juan Antonio Fierro Cubiella, "Un cuadro de Santa Cruz ¿obra de Valdés Leal?", Diario de Cádiz, 7 de marzo de 2000, p. 34.

Fierro Cubiella 2014: Juan Antonio Fierro Cubiella, "El enigmático cuadro de Santa Cruz", Diario de Cádiz, 2 de mayo de 2014.

Jerónimo de la Concepción 1690: Jerónimo de la Concepción (O.C.D.), Emporio del Orbe: Cádiz Ilustrada, (Ámsterdam, Imprenta de Joan Bus: 1690).

Kinkead 2009: Duncan T. Kinkead, Pintores y doradores en Sevilla: 16501699. Documentos, (Bloomington, Indiana: AuthorHouse, 2009), 2a edición revisada.

Lamas-Delgado 2014: Eduardo Lamas-Delgado, "Le peintre Bernabé de Ayala et autres petits maîtres entre Séville et Cadix", Annales d'Histoire de l'art et d'archéologie, no 36, (2014), pp. 71-94.

Lamas-Delgado 2015: Eduardo Lamas-Delgado, "El pintor Miguel Legot (Sevilla, c. 1627-Cádiz, 1695)", El Rincón malillo, no 5, (2015), pp. 47-52.

Quiles García y Alonso de la Sierra 1998: Fernando Quiles García y Lorenzo Alonso de la Sierra Fernández, "Nuevas obras de Cornelio Schut el Joven", Norba: Revista de Arte, no 18-19, (1998-1999), pp. 83-104.

Romero Dorado 2017: Antonio Romero Dorado, "Iniciando el catálogo del pintor Antonio Hidalgo: las Ánimas del Purgatorio (1688)", Philostrato. Revista de Historia y Arte, no 2, (2017), pp. 65-69. 
Sánchez López 2006: Andrés Sánchez López, La pintura de bodegones y floreros en España en el siglo XVIII, (Madrid: Universidad Complutense, 2006), tesis doctoral.

Valdivieso 2003: Enrique Valdivieso, Pintura barroca sevillana, (Sevilla: Ediciones Guadalquivir, 2003).

Viñaza 1889: Cipriano Muñoz y Manzano, Conde de la Viñaza 1866-1933, Adiciones al diccionario histórico de Ceán Bermúdez, (Madrid: Tipografía de los huérfanos, 1889), volumen II.

Recibido: $29 / 12 / 2017$

Aceptado: 2/03/2018 